\title{
ORGANISMOS GENETICAMENTE MODIFICADOS
}

\author{
GENETICALLYMODIFIED ORGANISMS
}

Xavier, E.G*1, D.C.N. Lopes ${ }^{1}$ e M.D.P. Peters ${ }^{1}$

\begin{abstract}
'Departamento de Zootecnia. Faculdade de Agronomia Eliseu Maciel. Universidade Federal de Pelotas. UFPEL. Caixa Postal 354. CEP 96010-900. Pelotas, RS. Brasil. *egxavier@yahoo.com
\end{abstract}

\section{Palavras chave adicionais}

OGM. Transgênicos. Genoma.

\section{RESUMO}

Os organismos geneticamente modificados (OGMs) são manipulados de modo a favorecer características desejadas pelo homem, sofrendo alterações no genoma realizadas através da tecnologia do DNA recombinante ou engenharia genética. Estas técnicas, referentes à biotecnologia, vêm apresentando um desenvolvimento rápido, o que tem contribuído para a obtenção de novos produtos, antes considerados impossíveis. Os avanços obtidos no campo da biotecnologia são significativos, incluindo a área médica, plantas modificadas através da bioengenharia e a aplicação da biologia molecular. Mundialmente, pesquisas estão sendo desenvolvidas para avaliar os efeitos dos organismos geneticamente modificados no que diz respeito ao cultivo, produtividade, impacto ambiental, consumo humano e animal. Desta forma, esta revisão tem como objetivos apresentar uma visão geral dos OGMs, alguns dos principais alimentos geneticamente modificados de origem animal e vegetal, bem como a sua aplicação na alimentação.

\section{SUMMARY}

Genetically modified organisms (GMOs) are developed for improving a group of specific desired characteristics. Such modifications take place in the genome and are carried out through recombinant DNA technology or genetic engineering. Biotechnology techniques are showing a fast development contributing for the new generation of a certain group of products, which in the past were considered impossible. The advances obtained in the biotechnology area are enormous, including medical area, genetically modified plants

\author{
AdDITIONAL KEYWORDS \\ GMO. Transgenics. Genoma.
}

and molecular biology. Studies have been conducted in different countries around the world to evaluate the main effects of genetically modified organism in terms of its cultivation, productivity, environmental impact, and human and animal consumption. Therefore, the objectives of this review are to show a general viewing of GMOs and also to present some of the animal and vegetable genetically modified feedstuffs along with its utilization in diets.

\section{INTRODUÇÃO}

Organismo geneticamente modificado (OGM), segundo o art. $3^{\circ}$, inciso V, da Lei Federal brasileira $\mathrm{n}^{\circ} 11.105$, de 24 de março de 2005, é o organismo cujo material genético (DNA/RNA) foi modificado por qualquer técnica de engenharia genética, excluídos desta classificação os organismos resultantes de técnicas que impliquem na introdução direta, num organismo, de material hereditário, desde que não envolva a utilização de moléculas de DNA/RNA recombinante ou OGM, tais como: fecundação in vitro, conjugação, transdução, transformação, indução poliplóide e qualquer outro processo natural.

Segundo Chaves (2006), técnicas de alterações em trechos do genoma realizadas através da tecnologia do DNA recombinante ou engenharia genética permitem que o homem manipule a molécula de DNA, através da clivagem, separação de fragmentos, 
amplificação e sequenciamento de DNA, hibridação de ácidos nucléicos, isolamento de genes e clonagem molecular.

A biotecnologia é a aplicação de informação e metodologia científica para a solução de problemas biológicos encontrados tanto na agricultura e pecuária, como na medicina, sendo originária da biologia e da tecnologia. Biologia vem a ser o conhecimento e estudo de organismos vivos e processos vitais e a tecnologia, por sua vez, é uma ciência aplicada e um método científico para se garantir um propósito prático. Muitos utilizam o termo biotecnologia como uma referência às ferramentas da engenharia genética desenvolvidas desde 1973, quando o Dr. Paul Boyer, na Califórnia, nos Estados Unidos da América (EUA), obteve em laboratório uma cepa recombinante da bactéria Escherichia coli capaz de expressar o gene da insulina humana. Entretanto, a biologia, a tecnologia, e as modificações genéticas dirigidas por humanos fazem parte da agricultura desde o começo da utilização de plantas cultivadas, há cerca de 10 mil anos.

A biotecnologia e o sistema convencional de melhoramento genético apresentam o mesmo objetivo, ou seja, incrementar ou melhorar as características desejáveis de uma planta ou de um animal. Por exemplo, o aumento do valor nutricional do arroz ou aumento do teor protéico do leite. No entanto, a biotecnologia é mais precisa, permitindo seleção criteriosa de um determinado gene, responsável por uma característica específica de um organismo vivo, e a sua transferência para outro organismo. Já o sistema convencional de melhoramento, com o objetivo de obter a característica desejada nas novas linhas genéticas, combina todas as características de ambos os pais. Por exemplo, a realização do cruzamento de uma variedade de milho altamente produtora com outra que apresente uma rápida velocidade de maturação, tem como objetivo obter uma nova linhagem contendo ambas as características desejáveis. Entretanto, na maioria das vezes, juntamente com as características desejáveis, são transferidas outras que não se tem interesse algum. Outra diferença entre a biotecnologia e o melhoramento convencional é o fato da biotecnologia permitir aos cientistas realizarem a transferência de características específicas entre bactérias, plantas, animais e seres humanos, o que não é possível através do melhoramento convencional, em função da incompatibilidade sexual interespecífica.

Pesquisadores são capazes de identificar o gene (ou os genes) responsável por características específicas, tais como resistência a doenças ou composição nutricional, realizar a sua inserção em outro organismo e obter os resultados em curto período de tempo. Esse mecanismo, embora seja considerado um dos mais controversos da biotecnologia, tem demonstrado alguma importância, como na produção do coalho (usado na produção de queijo) e de interferon (usado no combate ao câncer) (Vantreese, 2001).

A biotecnologia tem sido utilizada como uma ferramenta para a produção de alimentos, desde que os primeiros melhoristas decidiram seletivamente semear os melhores vegetais ou cruzar os melhores animais. Praticamente todas as espécies de plantas domesticadas existentes na atualidade diferem de maneira significativa da sua forma selvagem original, em função da intervenção humana. Muitos alimentos têm sofrido um processo biotecnológico há centenas de anos, incluindo o pão feito com a utilização de fermento, o vinho produzido a partir da fermentação da uva, além de outros (Xavier et al., 2005).

As técnicas referentes à biotecnologia vêm apresentando um desenvolvimento rápido, nos últimos anos, o que tem contribuído sobremaneira para obtenção de novos produtos, antes considerados irreais. Os avanços obtidos no campo da agropecuária são significativos, onde três ondas de produtos desenvolvidas pela biotecnologia podem ser identificadas. De 


\section{ORGANISMOS GENETICAMENTEMODIFICADOS}

acordo com Russel (2004), a primeira envolveu principalmente a área médica; a segunda foi a de plantas modificadas através da bioengenharia; e a terceira, a aplicação da biologia molecular. Esta última onda foi utilizada na fabricação de determinados produtos de consumo, como a seda da teia de aranha, a qual foi obtida do leite de cabras transgênicas; fibras semelhantes à lã e copos de plástico descartáveis biodegradáveis, obtidos a partir do milho; vacinas orais de origem vegetal, como as batatas portadoras de vacina desenvolvida contra rotavírus e Escherichia coli enteropatogênica; tomates capazes de se desenvolver em solos de alta salinidade; plantas de tabaco capazes de restaurar a fertilidade do solo em regiões degradadas pela guerra, através da eliminação de resíduos tóxicos de explosivos a base de nitrogênio; suínos produzindo grandes quantidades de enzima fitase em suas glândulas salivares; e vacas e cabras produzindo leite com elevados níveis de proteína (Brophy et al., 2003), lisozima humana(Maga et al., 2006a), antígeno da malária (Behboodi et al., 2005), hormônio do crescimento (Salamone et al., 2006), enzima butirilcolinesterase (Baldassarre et al., 2008), além de outros.

No início dos anos 80, surgiram discussões a respeito da utilização de OGMs, tão logo os cientistas aprenderam a manipular os genes dos organismos vivos. Desde então, a oposição aos alimentos geneticamente modificados tem sido marcante na Europa e no Japão. Segundo Moreira (1998), as principais preocupações em relação ao uso de alimentos geneticamente modificados vêm a ser o medo da produção de proteínas alergênicas, da produção de compostos tóxicos, redução da qualidade nutricional dos alimentos e diminuição da biodiversidade.

Desta forma, esta revisão tem como objetivos proporcionar uma visão geral dos OGMs, além de apresentar alguns dos principais alimentos geneticamente modifi- cados de origem animal, de origem vegetal, bem como a sua aplicação na alimentação.

\section{HISTÓRICO}

A biotecnologia teve seu início com os processos fermentativos, cuja utilização transcende o início da era Cristã, confundindo-se com a própria história da humanidade. A produção de bebidas alcoólicas pela fermentação de grãos de cereais já era conhecida pelos sumérios e babilônios antes do ano 6000 a.C. Posteriormente, por volta de 2000 a.C., os egípcios, que já utilizavam o fermento para a produção de cerveja, passaram a empregá-lo também na fabricação de pão. Outras aplicações, como a produção de vinagre, iogurte e queijos são, desde muito tempo, utilizadas pelo ser humano.

Louis Pasteur, em 1860, desenvolveu a técnica da pasteurização, definindo a função dos microorganismos e estabelecendo a ciência da microbiologia. Além disso, Pasteur provou que cada tipo de fermentação era realizada por um microorganismo específico e que este podia viver e se reproduzir na ausência de ar.

Mendel, em 1865, a partir de experimentos com ervilhas concluiu que existiam fatores (anos mais tarde identificados como genes) responsáveis pela transmissão de caracteres hereditários. Posteriormente, em 1897, Eduard Buchner, demonstrou ser possível a conversão de açúcar em álcool, utilizando células de levedura maceradas, ou seja, na ausência de organismos vivos. Paradoxalmente, foram as grandes guerras mundiais motivadoras da produção em escala industrial de produtos advindos de processos fermentativos. A partir da primeira guerra mundial, a Alemanha, que necessitava de grandes quantidades de glicerol para a fabricação de explosivos, desenvolveu, através de Neuberg, um processo microbiológico de obtenção desse álcool. Por outro lado, a Inglaterra produziu em grande quantidade a acetona para a 
fabricação de munições, tendo essa fermentação contribuído para o desenvolvimento dos fermentadores industriais e técnicas de controle de infecções.

Por volta de 1922, produtores americanos utilizaram pela primeira vez o milho hibrído, colaborando para o aumento da produção americana de milho em mais de $800 \%$, entre 1930 e 1985 . A partir de 1928 , com a descoberta da penicilina por Alexandre Fleming, diversos tipos de antibióticos foram desenvolvidos no mundo, sendo este o grande marco de referência na fermentação industrial.

$\mathrm{Na}$ década de 40, durante a segunda guerra mundial, os antibióticos passaram a integrar os processos industriais fermentativos, principalmente nos EUA, baseandose inicialmente na síntese da penicilina e, posteriormente, da estreptomicina. A partir da década de 50, a biotecnologia passou de fato a existir, com a descoberta da síntese química do DNA e com as técnicas de manipulação genética: DNA recombinante, fusão celular ou hibridoma. Em 1953, James Watson e Francis Crick publicaram na revista Nature a estrutura tridimensional do DNA em dupla hélice. Essa descoberta revolucionou a genética, pois forneceu informações fundamentais para o estudo e o desenvolvimento de técnicas de manipulação do DNA.

Na década de 70, com a modificação da E. coli para expressar o gene da insulina humana, iniciou-se a utilização de técnicas de engenharia genética por Cohen e Boyer, na Califórnia (EUA). Posteriormente, em 1983, ocorreu a aprovação da comercialização e do uso da insulina recombinante na medicina humana. Neste mesmo ano, uma técnica de amplificação de DNA in vitro (Reação em Cadeia da Polimerase ou PCR), foi desenvolvida por Kary Mullis, possibilitando a produção de inúmeras cópias ou fragmentos de genes. Mais tarde, tornou-se uma das principais ferramentas nas pesquisas biotecnológicas (Chaves, 2006). Ainda na década de 80 , através da biotecnologia, obteve-se a enzima utilizada na fabricação de queijos, a quimosina, permitindo o incremento da produção e a uniformidade do produto.

Em 1994, o tomate de amadurecimento retardado (Flavr Savr ${ }^{\mathrm{TM}}$ ) foi o primeiro alimento geneticamente modificado a entrar na cadeia alimentar norte americana. Em 1995, ocorreu a primeira liberação da importação e do plantio da soja geneticamente modificada, pelos Estados Unidos da América. No ano seguinte, a Argentina liberou a importação e o plantio de soja transgênica. Ainda na década de 90 foi criada, no Brasil, a Lei Brasileira de Biossegurança (Lei 8.974, de 5 de janeiro de 1995), e formou-se a Comissão Técnica Nacional de Biossegurança (CTNBio), sendo desde então considerada o órgão controlador de produtos transgênicos. Outro marco da biotecnologia foi o nascimento de duas ovelhas com gene humano, que produziram leite com proteína anticoagulante usada para hemofílicos. Posteriormente, em 1998, a União Européia aprovou as regras para etiquetagem de alimentos geneticamente modificados e em 1999, começou a vigorar o Protocolo de Cartagena, primeiro acordo internacional sobre o transporte de OGMs. Neste mesmo ano, foi fundada a Associação Nacional de Biossegurança (ANBio), sendo que em 2005 foi aprovada uma nova Lei Brasileira de Biossegurança (Lei 11.105, de 24 de março de 2005), voltada para o fortalecimento das ações em biossegurança no Brasil (Xavier et al., 2005).

Pesquisadores americanos somaram a técnica de transferência nuclear à experiência conhecida como manipulação genética, ou seja, criar em laboratório animais transgênicos, com genes da mesma espécie ou de espécies diferentes. Atualmente, é possível excisar regiões de DNA específicas, determinar a seqüência nucleotídica de um segmento, amplificar o DNA, produzindo um número elevado de cópias, isolar genes, modificá-los por engenharia genética e reintroduzí-los em células e organismos, e 


\section{ORGANISMOS GENETICAMENTE MODIFICADOS}

ainda conhecer os mecanismos de regulação e de expressão gênica (Chaves, 2006).

\section{MECANISMOSDE REGULAMEN- TAÇÃODOSORGANISMOS GENETICAMENTEMODIFICADOS}

A União Européia estabeleceu regulamentação referente aos OGMs, publicada em outubro de 2003, o que encerrou uma moratória de cerca 4 anos de pedidos de autorização para tais produtos (McCartney, 2004). Logo após a publicação da regulamentação, cerca de 20 pedidos referentes a OGMs, muitos dos quais encontravam-se retidos devido à moratória, foram encaminhados à União Européia. A regulamentação sobre os OGMs aplica-se não somente aos OGMs em si, mas também aos produtos derivados dos mesmos e está em vigor desde abril de 2004. Além disso, as rações e os ingredientes deverão ser passíveis de rastreamento em toda a cadeia alimentar, e registros, por escrito, deverão ser mantidos por um período mínimo de 5 anos e prontamente disponibilizados quando solicitados. A União Européia manterá um registro central para os OGMs, com a sua devida identificação. Os alimentos derivados de OGMs deverão receber um rótulo específico, e animais alimentados com rações contendo OGMs não serão considerados OGMs e, portanto, não serão rotulados como tal. Tais fatores são de extrema importância e devem ser considerados principalmente por aqueles países exportadores de rações ou ingredientes contendo OGMs para a União Européia, uma vez que a mesma consta de 25 países membros (estando a sua maioria entre os mais ricos do mundo) e de uma exigente população de cerca de 450 milhões de pessoas, correspondendo aos principais importadores mundiais de alimentos.

Existem, na atualidade, dois modelos principais para o controle de riscos dos produtos provenientes da biotecnologia, que são os chamados modelos regulatórios: o modelo regulatório baseado no controle da tecnologia da produção e o modelo regulatório baseado na avaliação do produto final (Chaves et al., 2003). O primeiro modelo é adotado na União Européia e no Brasil. O modelo entende que a tecnologia do DNA recombinante apresenta riscos específicos, e tem como pressuposto básico a análise caso a caso, incorporando o Princípio da Precaução, que diz que a ausência de certeza científica sobre a segurança de um produto não impede que medidas preventivas sejam adotadas para prevenir os riscos. O modelo estabelece procedimentos para a avaliação de riscos de OGMs, tanto em contenção quanto no caso de sua liberação para o ambiente. Tais procedimentos não têm por objetivo a criação de mecanismos de impedimento do desenvolvimento da tecnologia, mas sim o fornecimento de instrumentos para uma análise caso a caso, permitindo uma maior garantia de segurança para a saúde humana, animal e ambiental (Chaves et al., 2003). O segundo modelo, aquele baseado na avaliação do produto final, é o adotado nos Estados Unidos da América e no Canadá. O modelo entende como essencial para a análise de risco as características do produto final, independente de seu processo tecnológico de produção. O produto é avaliado com o mesmo rigor, independente de como é obtido. O princípio adotado não é o da precaução, mas sim da Equivalência Substancial, ou seja, se um produto geneticamente modificado apresenta características equivalentes às apresentadas por seu similar convencional, os mesmos são considerados equivalentes. Tanto o modelo regulatório baseado no controle da tecnologia da produção, como o modelo regulatório baseado na avaliação do produto final apresentam as mesmas exigências de inocuidade, estabilidade e segurança ambiental, sendo que o princípio básico é o de garantir a segurança humana, dos animais e do ambiente.

Independente do modelo regulatório 
empregado, cada país ou região apresenta mecanismos responsáveis por controlar a produção e utilização de OGMs. A União Européia possui a Autoridade Européia de Segurança de Alimentos, que atua na comissão européia em todos os aspectos de segurança de alimentos, inclusive na avaliação dos OGMs. Possui também o Sistema de Alerta Rápido para Alimentos e Rações, o qual engloba os 25 países membros e trabalha em conjunto com outro órgão, o Escritório de Alimentos e Veterinária, para assegurar que todos os alimentos destinados ao consumo dentro da União Européia estejam de acordo com todas as legislações relevantes à comunidade.

Nos EUA, alimentos produzidos a partir das técnicas de biotecnologia precisam cumprir com todas as exigências estabelecidas pelo Food and Drug Administration (FDA) para todos os alimentos. Além do FDA, outras duas agências são responsáveis pelo controle do desenvolvimento de alimentos através da biotecnologia: a Agência de Proteção Ambiental Norte Americana, que regula o impacto ambiental do produto, e o Departamento de Agricultura Norte Americana, que por sua vez apresenta várias agências envolvidas, incluindo o Serviço de Inspeção Sanitária Animal e Vegetal, o Serviço de Inspeção de Segurança de Alimentos, o Serviço de Pesquisa Agrícola, o Serviço de Pesquisa Econômica, e o Serviço Cooperativo Nacional de Pesquisa, Educação, e Extensão.

No Brasil, a lei 11.105 de março de 2005 (que revogou a lei anterior, 8.974, de janeiro de 1995) regulamenta o uso de técnicas de bioengenharia e a liberação de OGMs no ambiente. Tal legislação foi responsável pela criação da Comissão Técnica Nacional de Biossegurança (CTNBio), ligada ao Ministério da Ciência e Tecnologia. Cabe a CTNBio prestar apoio técnico consultivo e de assessoramento ao Governo Federal na formulação, atualização e implementação da Política Nacional de Biossegurança relativa a OGMs, bem como no estabelecimento de normas técnicas de segurança e pareceres técnicos conclusivos referentes à proteção da saúde humana, dos organismos vivos e do meio ambiente, para atividades que envolvam a construção, experimentação, cultivo, manipulação, transporte, comercialização, consumo, armazenamento, liberação e descarte de OGM e derivados.

\section{ORGANISMOS GENETICAMENTE MODIFICADOSDE ORIGEM VEGETAL E SEU USO NA ALIMENTAÇÃO}

Em 1994, conforme mencionado anteriormente, foi introduzido no mercado o primeiro alimento geneticamente modificado, o tomate Flavr Savr ${ }^{\mathrm{TM}}$, cuja principal característica vem a ser o seu amadurecimento retardado, possibilitando maior "vida de prateleira", sem perder a suculência e a maciez. No caso do Flavr SavrTM, os cientistas conheciam a existência de uma enzima, poligalacturonase (PG), responsável pelo incremento da sua maciez de acordo com o amadurecimento, bem como por prolongar o período de amadurecimento. Quando isolaram o gene responsável pela expressão da enzima e o introduziram no genoma, o tomate manteve suas propriedades organolépticas por um período maior do que os tomates comuns. Essa técnica permitiu o desenvolvimento de tomates com um melhor sabor e que podem ser transportados a longas distâncias sem perder sua qualidade.

Em 1995, a Agência de Proteção Ambiental Norte Americana aprovou o plantio e a comercialização da soja tolerante ao herbicida glifosato (Roundup Ready ${ }^{\circledR}$ ). Antes disso, foram vários anos de testes de alimentos e drogas nos Estados Unidos da América para que o Departamento de Agricultura daquele país liberasse o seu plantio e comercialização. Devido a elevada utilização de produtos derivados da soja como ingredientes alimentares, estima-se que a maioria dos consumidores norte americanos esteja consumindo alimentos 


\section{ORGANISMOS GENETICAMENTE MODIFICADOS}

obtidos a partir da engenharia genética.

Existe atualmente uma quantidade considerável de alimentos geneticamente modificados de origem vegetal, envolvendo canola, morango, mamão, manga, pimentão, algodão, batata, abóbora, arroz, trigo, dentre outros. O arroz é um ingrediente comum na mesa de diversos povos, entretanto, o mesmo apresenta deficiência de vitamina A, o que pode levar a problemas de cegueira. Assim, o arroz foi geneticamente modificado para conter quantidade suficiente de beta-caroteno (precursor da vitamina A), passando então a ser um suplemento de vitamina A para crianças com problemas de desnutrição, e foi denominado de arroz dourado (golden rice) (Russel, 2004). Na mesma linha de pesquisa do arroz dourado, outras linhagens de arroz estão sendo desenvolvidas com o objetivo de fornecer maiores quantidades de beta-caroteno e também de ferro, neste caso diminuindo o problema da anemia. Além do arroz, foram desenvolvidas batatas com capacidade de absorver menor quantidade de óleo (o que pode reduzir a incidência de doenças cardiovasculares), amendoins que não causam alergia, bananas contendo vacina contra a Hepatite B e outras doenças, batatas portadoras de vacina contra rotavírus e Escherichia coli enteropatogênica, oleaginosas contendo óleos mais saudáveis, grãos de soja contendo altos níveis de lisina e de ácido oléico, tomates aptos a se desenvolver em solos com elevado grau de salinidade, para a produção de antibióticos, dentre outros.

Segundo relatório de 2007 da International Service for Acquisition of AgriBiotech Applications (ISAAA), a área mundial cultivada com plantas geneticamente modificadas, em 2007, foi de 114,3 milhões de hectares, o que significou um aumento de $12 \%$ em relação ao ano anterior. Os hectares cultivados acumulados de 1996 a 2007 ultrapassaram dois terços de um bilhão de hectares, com um aumento de sessenta e sete vezes entre 1996 e 2007, fazendo da biotecnologia a tecnologia agrícola de mais rápida adoção dos últimos tempos. Em 2007, os EUA, seguidos pela Argentina, Brasil, Canadá, Índia e China continuaram sendo os maiores adeptos às lavouras geneticamente modificadas, com os EUA ocupando o primeiro lugar mundialmente, com 57,7 milhões de hectares $(50 \%$ da área global com lavouras derivadas da biotecnologia) motivados por um mercado crescente de etanol, com uma área plantada com milho GM aumentando em uma taxa significativa de 40\% (James, 2007).

A biotecnologia oferece ainda outras alternativas aos ingredientes tradicionalmente utilizados na alimentação, como o milho e a soja resistentes a insetos (milho Bt e soja Bt) e tolerantes a herbicidas (Roundup Ready () ). Surgiram, portanto, cultivares com maior resistência a insetos e a doenças, sem a necessidade da utilização de volumes elevados de inseticidas e herbicidas, com a conseqüente diminuição de custos e do impacto ambiental, além de apresentarem menores riscos de perdas e maior qualidade dos produtos.

Segundo James (2007), a cultura transgênica mais cultivada em 2007 foi a da soja (57\% da área total cultivada com plantas transgênicas), com uma área aproximada de 58,6 milhões de hectares, seguida do milho (35,2 milhões de hectares), algodão (15 milhões de hectares) e canola (5,5 milhões de hectares). Desde o início da comercialização desses produtos, de 1996 a 2007, a tolerância a herbicidas tem sido a característica predominante. Em 2007, a tolerância a herbicidas, empregada na soja, milho, canola, algodão e alfafa ocupou $63 \%$ ou 72,2 milhões de hectares da área global de lavouras GM, de 114,3 milhões de hectares. Entretanto, cultivares apresentando a combinação de dois ou três genes vem ocupando uma área maior (21,8 milhões de hectares) do que as resistentes a insetos (20,3 milhões de hectares).

Todavia, o consumo de ingredientes geneticamente modificados ainda gera uma 
grande discussão em relação aos riscos à saúde humana e animal. Em função disso, diversas pesquisas foram desenvolvidas buscando comparar a qualidade nutricional das variedades geneticamente modificadas com a das variedades comerciais tradicionalmente utilizadas (Padgette et al., 1996). Da mesma forma, foram desenvolvidas pesquisas visando avaliar o desempenho, características de carcaça, e a sanidade dos animais consumindo alimentos geneticamente modificados, em comparação com o consumo de ingredientes tradicionais.

Um dos primeiros experimentos utilizando milho Bt e soja Bt como ingredientes nas dietas de suínos e aves foi conduzido por Brake e Vlachos (1998), onde verificaram que aves alimentadas com milho Bt apresentaram desempenho semelhante àquelas alimentadas com milho comum, sem apresentar efeito negativo na carcaça. Outros trabalhos foram realizados avaliando o efeito do fornecimento de dietas contendo milho Bt e soja Bt, em comparação com milho e soja comuns, para suínos e aves, demonstrando a equivalência nutricional entre os mesmos e a ausência de diferença no desempenho, mineralização óssea, características de carcaça, sanidade e qualidade do ovo (Hammond et al., 1996; Ash et al., 2000; Mireles Jr. et al., 2000; Sidhu et al., 2000; Weber et al., 2000; Cromwel et al., 2002; Brake et al., 2003; Taylor et al., 2003a, 2003b; Hyun et al., 2004; Kan e Hartnell, 2004; Flachowsky et al., 2005; Halle et al., 2006; Jacobs et al., 2008). Foi também avaliado o efeito da silagem produzida com milho Bt sobre a produção e composição do leite, $\mathrm{pH}$ ruminal, e a relação acetato: propionato em vacas leiteiras. Não foi verificado efeito negativo do milho Bt sobre os parâmetros avaliados, não havendo diferenças significativas entre o milho Bt e o convencional (Folmer et al., 2000). Outros estudos visando avaliar o efeito do fornecimento de milho $\mathrm{Bt}$, em comparação com o milho comum, para vacas leiteiras, foram realizados e não foram obtidas diferenças com relação ao consumo de alimento, produção de leite, níveis de gordura, proteína, lactose e sólidos totais no leite (Clark e Ipharraguerre, 2001).

Um total de dezoito experimentos foram realizados utilizando alimentos geneticamente modificados (milho Bt, milho tolerante ao glufosinato (milho PAT), beterraba PAT, soja Roundup Ready ${ }^{\circledR}$, batata Bt e batata Roundup Ready ${ }^{\circledR}$ ) na dieta de bovinos de corte e leite, suínos em crescimento e terminação, galinhas de postura, frangos e codornas de corte, e codornas de postura. Em todos os experimentos, o alimento geneticamente modificado foi comparado com a variedade comum isogênica. Foi avaliado o desempenho, o consumo de ração e o estado sanitário dos animais, além da digestibilidade de nutrientes da dieta. Não foram encontradas diferenças significativas no valor nutricional dos alimentos geneticamente modificados em comparação com as variedades comuns, corroborando com mais de cem estudos realizados até o momento (Flachowsky et al., 2007).

\section{ALIMENTOS COMBAIXOTEORDE FÓSFORO}

O fósforo $(\mathrm{P})$ é um mineral de grande importância para os animais, uma vez que apresenta diversas funções no organismo, estando presente em todas as células e envolvido em várias reações metabólicas. Devido a sua importância, quantidades adequadas de $\mathrm{P}$ disponível precisam estar presentes na dieta para o crescimento, desenvolvimento e reprodução, assim como para o desenvolvimento ósseo. Entretanto, a maioria do $P$ presente nos grãos de cereais e em farelos de oleaginosas, componentes típicos das dietas de não-ruminantes, encontra-se ligado a um complexo molecular denominado de ácido fítico. Nãoruminantes, por não apresentarem quantidades suficientes da enzima fitase no seu trato digestório, são incapazes de utilizar o P ligado ao ácido fítico, eliminando grande quantidade deste mineral nas fezes e na 


\section{ORGANISMOS GENETICAMENTE MODIFICADOS}

urina, com conseqüente impacto ambiental.

Uma alternativa que foi desenvolvida, objetivando reduzir a quantidade de $\mathrm{P}$ excretado no ambiente, foi a redução da quantidade de $\mathrm{P}$ não disponível presente nos grãos. Mutações, denominadas lpa (low-phytic acid), foram isoladas e tornaramse fundamentais para o entendimento das vias metabólicas do ácido fítico. Além disso, as mutações lpa forneceram os materiais genéticos necessários para a obtenção da primeira geração de híbridos lpa, cultivares e linhagens de milho (low-phytate corn), soja (low-phytate soybean), cevada (lowphytate barley) e arroz (low-phytate rice), dentre outras, contendo baixos níveis de ácido fítico (Larson et al., 1998; Raboy et al., 2000; Raboy, 2002). Adicionalmente, plantas de soja contendo baixos níveis não somente de ácido fítico, mas também de oligossacarídeos foram desenvolvidas, sendo estes também considerados fatores anti-nutricionais (Sebastian et al., 2000; Hitz et al., 2002). Em comparação com outras cultivares e híbridos, ou mesmo com plantas nativas, linhagens lpa podem ser consideradas como sendo geneticamente modificadas. Entretanto, de acordo com a maioria das definições, para ser considerado um OGM, a linhagem desenvolvida deve ser transgênica, ou seja, deve apresentar genes de outras espécies introduzidas em seu genoma, o que não é o caso das linhagens lpa (Raboy, 2001). Grãos de cereais e de soja lpa, quando combinados, oferecem uma importante fonte de $\mathrm{P}$ altamente disponível para suínos e aves, permitindo a redução da necessidade da suplementação com $\mathrm{P}$ inorgânico e da quantidade de enzima fitase adicionada às dietas, além da conseqüente diminuição na quantidade de $\mathrm{P}$ excretado.

Estudos de biodisponibilidade de $\mathrm{P}$ realizados com suínos em crescimento mostraram valores que variaram entre $62 \mathrm{e}$ $69 \%$ para o milho lpa e entre 9 e $22 \%$ para milho comum isogênico (Cromwell et al., 1998a; Spencer et al., 1998, 2000a). O milho lpa apresentou uma biodisponibilidade quase três vezes maior do que o comum. 0 recebendo dietas contendo a combinação de milho e farelo de soja comuns (Cromwell et al., 2000; Spencer et al., 2000b; Xavier, 2003). De maneira semelhante, foram realizados experimentos com cevada lpa, onde verificou-se um incremento na biodisponibilidade de $P$ para peixes (Sugiura et al., 1999) e para aves (Li et al., 2001b), com uma redução significativa na excreção de $\mathrm{P}$ por aves (Li et al.,2001a) e por suínos (Veum et al.,2002), quando alimentados com dietas contendo cevada lpa.

A enzima fitase (mio-inositol hexaquisfosfato fosfohidrolase), quando suplementada às dietas de não-ruminantes, vem a ser uma outra alternativa para a redução da quantidade de $\mathrm{P}$ excretada no ambiente. A enzima hidroliza o ácido fítico em ortofosfato inorgânico e uma série de ésteres fosfóricos menores, até o mio-inositol monosfato (Kies, 1999; Nys et al., 1999). Cromwell et al. (1993) demonstraram aumentos na biodisponibilidade de $\mathrm{P}$ de $15 \%$ para mais de $45 \%$ com a suplementação da enzima fitase à dietas a base de milho e farelo de soja para suínos em crescimento. A adição de fitase microbiana (Natuphos ${ }^{\circledR}$ G) em dietas para suínos em crescimento, contendo a combinação de milho e farelo de soja comuns, aumentou a biodisponibilidade de P de $34 \%$ para $63 \%$. Quando a enzima foi adicionada a dietas contendo a combinação de milho lpa e farelo de soja lpa, a biodisponibilidade de $\mathrm{P}$ aumentou de 80 a $90 \%$ (Xavier, 2003). Respostas semelhantes foram obtidas com frangos, aumentando a biodisponibilidade de $\mathrm{P}$ de 34 (dietas contendo a combinação de milho e soja comuns) para 59\% (mesmas dietas, com a adição de fitase) e de 71 (dietas contendo a combinação de milho lpa e farelo de soja lpa) para $88 \%$ (mesmas dietas, com a adição de fitase) (Xavier, 2003). Com relação à excreção de $\mathrm{P}$, houve uma redução de $36 \%$ com a adição de fitase à dietas convencionais, e de $70 \%$ quando adiciona- 
da à dietas contendo milho lpa e soja lpa, para suínos em crescimento (Xavier, 2003), resultados significativos para a diminuição da poluição ambiental causada pela suinocultura e pela avicultura.

\section{ORGANISMOSGENETICAMENTE MODIFICADOSDE ORIGEM ANIMAL}

Animal transgênico pode ser definido como aquele que apresenta moléculas de DNA recombinante exógenas introduzidas em seu genoma por intervenção humana através da bioengenharia (Pereira, 2008).

A biotecnologia também tem sido utilizada para a obtenção de animais transgênicos, com diferentes objetivos, sendo a maioria das pesquisas direcionadas para a área agropecuária, médica humana e indústria.

Suínos, aves, bovinos leiteiros, ovinos, caprinos e peixes são exemplos de algumas das espécies que estão passando por programas de bioengenharia visando a obtenção de uma gama de novas proteínas, sendo a maioria, também, direcionada para a agropecuária, medicina humana e indústria. Um dos benefícios obtidos é o fato de a proteína desejada poder ser obtida no sangue, no leite, ou em ovos, o que facilita a sua extração e purificação. Como exemplos foram obtidos dois caprinos por bioengenharia, os quais foram denominados Webster e Peter, sendo cada um deles portador de um gene para a produção de material de teia de aranha. Tais animais foram usados como reprodutores para a criação de um rebanho de caprinos leiteiros aptos a produzir as proteínas da seda da teia de aranha em seu leite. As proteínas são extraídas do leite e fiadas em fibras, criando uma seda especial denominada BioSteel ${ }^{\circledR}$ (Russel, 2004). As fibras BioSteel ${ }^{\circledR}$ estão sendo pesquisadas pelo exército norte americano e canadense visando o desenvolvimento de materiais e equipamentos para proteção individual, pois oferecem maior resistência e flexibilidade do que o aço, além de maior leveza, sendo uma alternativa para o desenvolvimento de equipamentos para aeronaves, veículos de corrida e coletes à prova de bala, além de tendões artificiais, ligamentos e próteses.

Golovan et al. (2001), na Universidade de Guelph (Canadá), desenvolveram linhagens de suínos transgênicos, aos quais denominaram de Enviropig $₫$, cuja principal característica vem ser a produção de grandes quantidades da enzima fitase na sua saliva. Os pesquisadores canadenses desenvolveram 33 linhagens de suínos transgênicos, das quais 14 foram aptas a produzir altos níveis de fitase microbiana (Escherichia coli) nas glândulas salivares. Foram obtidos elevados níveis de digestibilidade verdadeira de $P$ no farelo de soja, entre 88 e quase $100 \%$. Além disso, a excreção de $\mathrm{P}$ foi reduzida em $75 \%$ em suínos em crescimento, e $56 \%$ em suínos em crescimento-terminação, sem qualquer efeito negativo na sanidade ou no desempenho dos animais. Segundo os pesquisadores canadenses, a provável razão da maior eficiência da enzima fitase no Enviropig ${ }^{\circledR}$ vem a ser a grande quantidade de enzima continuamente presente no estômago dos suínos, com uma liberação de cerca de 200000 unidades de fitase para o trato digestório durante o consumo de $1 \mathrm{~kg}$ de alimento. Em um futuro não muito distante o Enviropig ${ }^{\circledR}$ poderá vir a ser mais uma importante alternativa para o problema da poluição ambiental causada pela suinocultura.

Recentes pesquisas demonstram que a tecnologia para produção de animais transgênicos pode resultar em produtos de origem animal com funções nutricionais específicas para o organismo humano e animal, podendo estes ser considerados alimentos nutracêuticos. Produtos de origem animal, com exceção do óleo de peixe, apresentam baixos níveis de ácidos graxos ômega-3, os quais são sabidamente benéficos à saúde humana. Neste sentido, suínos transgênicos foram desenvolvidos com a capacidade de expressar o gene Caenorhabditis elegans, fat-1, que codifica a enzima desaturase do ácido graxo ômega-3 e 


\section{ORGANISMOS GENETICAMENTEMODIFICADOS}

apresentam altos níveis de ácidos graxos ômega-3 nos órgãos e tecidos, além de uma menor relação de ácidos graxos ômega-6/ ômega-3, trazendo assim, benefícios para a saúde humana (Lai et al, 2006; Prather, 2006). No Japão, foi desenvolvida uma técnica de reprodução de salmões objetivando a produção de alevinos de trutas. Foram criados salmões machos capazes de produzir esperma de uma espécie de truta bastante próxima. O esperma dos salmões, quando utilizado para fertilizar ovos de truta, produz alevinos de truta saudáveis. Tal descoberta pode ser usada para incrementar a produção de peixes em cativeiro e até para tentar reviver espécies extintas. É importante considerar que salmões e trutas estão separados por cerca de 8 milhões de anos de evolução (Russel, 2004). Esses estudos são exemplos de como a transgenia também pode ser utilizada para, além de aumentar o desempenho, melhorar características de carcaça e qualidade de carne de animais de interesse zootécnico.

Várias pesquisas foram realizadas utilizando animais transgênicos de produção expressando genes recombinantes capazes de produzir substâncias de interesse biomédico e farmacêutico no leite. Uma destas pesquisas foi desenvolvida por Behboodi et al. (2005), que avaliaram o estado sanitário, o desempenho reprodutivo e a produção de leite de cabras transgênicas expressando um gene recombinante de um antígeno da malária. Os pesquisadores observaram que as cabras que expressavam o antígeno não glicosilado da malária apresentaram produção de leite normal e produziram a proteína recombinante no leite. Este estudo demonstrou que é viável a produção de vacina contra a malária a partir do leite oriundo de animais transgênicos. Outros pesquisadores, objetivando estudar a produção de biofármacos no leite, realizaram um estudo com vacas transgênicas expressando no leite um gene recombinante do hormônio de crescimento humano semelhante ao produzido pela expressão na
Escherichia coli, e verificaram que estes animais, são capazes de produzir este hormônio no leite em quantidade significativa, tornando-se uma alternativa viável para produção deste hormônio (Salamone et al., 2006).

Cabras transgênicas foram desenvolvidas e estudadas por Maga et al. (2006a) com o objetivo de avaliar a produção e composição do leite destes animais expressando um gene recombinante da lisozima humana na glândula mamária. Os animais transgênicos apresentaram níveis de $270 \mathrm{~g} / \mathrm{mL}$ ou $68 \%$ do encontrado no leite humano, além de uma menor contagem de células somáticas, quando comparados aos animais não transgênicos. Não houve diferença na produção e demais constituintes do leite em relação ao grupo controle. De modo semelhante, Maga et al.(2006b) e Brundige et al. (2008) avaliaram os efeitos do fornecimento do leite com lisozima humana na dieta de leitões e observaram benefícios na microflora e integridade intestinal destes animais, pela ação antimicrobiana da lisozima. Os leitões que receberam o leite das cabras transgênicas apresentaram menor contagem de coliformes totais e de Escherichia coli no íleo, além de menor quantidade de linfócitos e uma maior vilosidade duodenal em comparação aos animais que receberam leite de cabra não transgênica. Os pesquisadores ressaltam que os benefícios obtidos podem ser interessantes quando o leite for fornecido para crianças, podendo melhorar o seu crescimento e desenvolvimento.

Com o objetivo de melhorar a composição do leite e a eficiência do seu processamento, Brophy et al. (2003) desenvolveram vacas transgênicas expressando genes adicionais para $\beta$ e $\kappa$-caseína, e observaram que houve um aumento de duas a três vezes na concentração de $\kappa$-caseína total, associado a um incremento de $13 \%$ no nível protéico do leite das vacas transgênicas, em comparação ao leite das vacas não geneticamente modificadas. $O$ aumento na 
concentração de caseína pode permitir a obtenção mais econômica de queijos. Mais recentemente, Laible et al. (2007) utilizaram vacas transgênicas similares as do estudo anterior para avaliar as características químicas do leite e do queijo, e observaram que não houve diferença na composição do leite das vacas transgênicas em comparação às não transgênicas, além de uma igual secreção de imunoglobulinas no colostro. Observaram, ainda, que o processamento do leite de vacas transgênicas resultou em um queijo com menor teor de gordura, maior teor de sal, além de maiores níveis de aminoácidos totais, com exceção da lisina.

Baldassarre et al. (2008) utilizaram cabras geneticamente modificadas expressando uma enzima humana recombinante, a butirilcolinesterase, e verificaram que a quantidade de butirilcolinesterase produzida pelas cabras transgênicas foi maior do que a encontrada no sangue dos humanos doadores do gene. Sabendo que esta enzima é utilizada em intoxicação contra organofosforados em humanos e animais, a produção de leite pelas cabras transgênicas torna-se uma alternativa para a produção da enzima utilizada como produto farmacêutico ou biodefensivo. As cabras estão entre os melhores modelos para a obtenção de animais transgênicos produtores de proteínas recombinantes no leite, como anticorpos e hormônios de crescimento, pois o custo de manutenção de criação destes animais é relativamente baixo, e apresentam ciclo reprodutivo curto (Huang et al., 2007).

Outro estudo foi realizado por Wall et al. (2005), com o objetivo de desenvolver vacas geneticamente modificadas capazes de produzirem lisostafina no leite. Estes animais ao serem submetidos a infusões intramamárias de Staphylococcus aureus apresentaram contagem de células somáticas e temperatura corporal normal em relação às vacas não transgênicas. No mesmo sentido, um estudo foi realizado por Hyvonen et al. (2006), que observaram uma produção de lactoferrina no leite de vacas transgênicas expressando um gene recombinante da lactoferrina humana. Os estudos demonstram que a engenharia genética pode melhorar a resistência do rebanho contra doenças, uma vez que melhoram os mecanismos de defesa não específica em nível de glândula mamária, aumentando assim o bem-estar animal.

Outra possibilidade para a utilização de animais transgênicos na área da medicina humana está relacionada à utilização de órgãos dos animais para a realização de xenotransplantes. A transgenia vem sendo utilizada para a criação de suínos imunocompatíveis com o ser humano, através da técnica de nocaute. Entretanto, a maior parte das espécies animais dispõe de uma enzima, a alfa 1,3 galactosyl transferase, responsável pela síntese do epítopo Gal alfa 1-3 beta Gal, que é comum a numerosas moléculas expressas na superfície das células endoteliais. Em certas espécies de primatas superiores, entre eles o homem, essa enzima foi abolida no decorrer processo evolutivo. Os primatas superiores e o homem não expressam, portanto, esse antígeno. Dessa forma, sintetizam naturalmente anticorpos contra o epítopo produzido. Assim, quando recebem o enxerto de um animal que apresente o epítopo nas células endoteliais, a reação é imediata. Nesse sentido, foi produzida uma linhagem de suínos que não expressa o epítopo Gal em seres humanos, e, atualmente, está sendo testado o transplante de corações, rins e ilhotas do pâncreas desses animais para macacos. No entanto, é importante ressaltar que, se por um lado o xenotransplante resolveria a questão da disponibilidade de órgãos para transplantes, cria uma outra questão séria de biossegurança, que é o risco de transmissão de patógenos suínos para o ser humano (Castro e Glotz, 2002; D'apice e Cowan, 2008; Pereira, 2008).

No momento, não existe possibilidade de realizar com êxito o xenotransplante sem antes modificar geneticamente os doadores de órgãos (animais), pois a modificação genética pode auxiliar na redução de alguns 


\section{ORGANISMOS GENETICAMENTEMODIFICADOS}

problemas, através da utilização de genes específicos, reduzindo a possibilidade de rejeição hiperaguda nos xenotransplantados, como necrose tecidual, trombose vascular e isquemia, que geralmente ocorre neste tipo de transplante (Castro e Glotz, 2002; D'Apice e Cowan, 2008). Como exemplo, pode-se utilizar genes antioxidantes (catalase, glutationa peroxidase e superóxido dismutase); genes contra a apoptose celular (A20); genes crioprotetores (CD39); e genes para facilitar a revascularização (VEGF), visando reduzir os problemas de isquemia; e genes inibidores da enzima alfa 1,3 galactosyl transferase (GAL-KO), visando a redução da imunossupressão sistêmica tóxica dos tecidos e órgãos dos doadores.

\section{OS POTENCIAIS RISCOSE BENEFÍCIOS DOSOGMS}

$\mathrm{Na}$ avaliação dos riscos associados com as novas técnicas de produção de alimentos, é necessário considerar também a maneira como essas técnicas diferem das tradicionais empregadas na agricultura. Quando são utilizados métodos tradicionais de melhoramento, visando incrementar alguma característica em uma planta, por exemplo, os níveis de toxinas que ocorrem naturalmente podem ser aumentados como resultado do cruzamento realizado. Desta forma, são necessários vários anos realizando-se outros cruzamentos para tentar livrar a nova planta da característica indesejável e, ao mesmo tempo, manter os benefícios do híbrido. De maneira semelhante, existem riscos associados aos altos níveis de produtos químicos utilizados atualmente, os quais permitem às culturas tolerarem insetos, doenças e condições climáticas adversas. Com o emprego das técnicas da biotecnologia, foram desenvolvidas novas variedades, muitas delas mais produtivas do que as tradicionalmente utilizadas.

Existem riscos naturais associados à produção de alimentos, como infecções, doenças, pragas, excesso de chuvas ou seca, entre outros, que podem comprometer significativamente. Assim, através do uso de plantas geneticamente modificadas, podem ser reduzidos significativamente estes riscos e outros problemas que causam queda na produção vegetal. Fitomelhoristas conseguiram introduzir em algumas variedades a proteção contra determinados insetos, como a lagarta do milho, o besouro e a lagarta da batata, e o gorgulho do algodão, por exemplo. Tais variedades geneticamente modificadas foram denominadas milho Bt, batata $\mathrm{Bt}$, e algodão $\mathrm{Bt}$, respectivamente, em função de expressarem um gene que codifica uma proteína de efeito inseticida, semelhante àquela produzida na natureza por algumas subespécies do Bacillus thuringiensis, uma bactéria comumente presente no solo, permitindo aos produtores reduzir o uso de produtos químicos nas lavouras. De forma semelhante, foram produzidas plantas de soja e de milho tolerantes a herbicidas, como o glifosato, permitindo a aplicação de herbicidas na lavoura para o controle de plantas daninhas sem afetar a cultura principal (Vantreese, 2001). Sementes produzidas através da bioengenharia permitem a obtenção de produções mais uniformes. Além disso, a semeadura de variedades protegidas contra doenças reduz a quantidade de herbicidas e inseticidas utilizados, aumentando a produtividade, diminuindo os custos de produção e os danos ao meio ambiente. Adicionalmente, o uso de novas tecnologias permite obter plantas com maior resistência à seca e maior eficiência na absorção de nutrientes do solo. Portanto, tais avanços obtidos podem ser considerados de extrema importância, particularmente para os países em desenvolvimento que sofrem com períodos de estiagem prolongada, erosão, infertilidade do solo, ataques de pragas, além de outros problemas.

Debates a respeito da utilização de organismos geneticamente modificados tiveram seu início tão logo os cientistas aprenderam 
a manipular os genes dos organismos vivos, no início dos anos 80. Desde então, a oposição aos alimentos geneticamente modificados tem sido especialmente forte na Europa e no Japão. As principais preocupações com relação ao uso dos alimentos transgênicos têm sua origem basicamente em função dos problemas ocorridos na produção de alimentos no final do século passado, principalmente no que se refere à doença da "vaca louca" (Encefalopatia Espongiforme Bovina-BSE) e a contaminação da cadeia de alimentos por dioxina. Entretanto, é interessante salientar que em nenhum dos casos os problemas foram causados por OGMs. Segundo Moreira (1998), as principais preocupações em relação ao uso de alimentos geneticamente modificados vêm a ser o medo da ocorrência de efeitos inesperados produzidos pela transferência de material genético, da produção de novas proteínas alergênicas, da produção de compostos tóxicos, e da redução da qualidade nutricional dos alimentos. Para verificar estas hipóteses, vários experimentos foram realizados com animais de interesse zootécnico, utilizando-se dietas contendo alimentos geneticamente modificados (milho Bt, milho tolerante ao glufosinato (milho PAT), beterraba PAT, soja Roundup Ready®, batata Bt e batata Roundup Ready $\left({ }^{\circledR}\right)$ e não foram observadas diferenças nos valores nutricionais, e nem tão pouco a presença de fragmentos de DNA recombinante em nenhum dos órgãos e tecidos dos animais alimentados com alimentos geneticamente modificados, em comparação às dietas contendo alimentos isogênicos (Flachowsky

\section{BIBLIOGRAFIA}

Ash, J.A., S.E. Scheideler and C.L. Novak. 2000. The fate of genetically modified protein from Roundup Ready soybeans in the laying hen. $J$. Poult. Sci., 79: 26-26.

Baldassarre, H., D.K. Hockley, D. Monique, E. Brochu, B. Hakier, X. Zhao and V. Bordignon. et al., 2007)

Adicionalmente, há o temor infundado de que determinados genes possam aumentar a resistência humana à antibióticos a partir do consumo, a longo prazo, de alimentos transgênicos, ou do consumo de animais que consumiram alimentos transgênicos. Além disso, existe o temor da diminuição ou perda da biodiversidade, de "super plantas", que possam resistir aos métodos tradicionais de controle. Entretanto, até o presente momento, nenhum desses temores foi associado a fatos concretos.

\section{CONSIDERAÇÕES FINAIS}

Com a presente revisão não se espera esgotar o assunto relacionado aos organismos geneticamente modificados (OGMs). Há diversas dúvidas a serem respondidas, principalmente no que se refere aos efeitos em longo prazo resultantes do consumo de OGMs, ou ainda, do consumo de animais que foram alimentados com OGMs, com relação ao desenvolvimento de alergias, por exemplo. Também há dúvidas relacionadas aos efeitos dos OGMs sobre a biodiversidade e a possibilidade de contaminação das variedades nativas pelas geneticamente modificadas, no meio ambiente, através da polinização. Assim, inúmeros estudos encontram-se em andamento nas mais diversas áreas, tais como na área médica, animal e vegetal, visando conhecer os efeitos, bem como responder aos questionamentos relacionados a OGMs. Até o presente momento, entretanto, não há a concretização de nenhum dos problemas referidos, com a utilização de OGMs.

2008. Lactation performance of transgenic goats expressing recombinant human butyrylcholinesterase in the milk. Transgen. Res., 17: 73-84.

Behboodi, E., S.L. Ayres, E. Memili, M. O'Coin, L.H. Chen, B.C. Reggio, A.M. Landry, W.G. Gavin, 


\section{ORGANISMOS GENETICAMENTE MODIFICADOS}

H.M. Meade, R.A. Godke and Y. Echelard. 2005. Health and reproductive profiles of malaria antigen-producting transgenic goats derived by somatic cell nuclear transfer. Clon. Stem. Cel., 7: 107-118.

Brake, J., and D. Vlachos. 1998. Evaluation of transgenic event 176 "Bt" corn in broiler chickens. J. Poult. Sci., 77: 648-653.

Brake, J., M.A. Faust and J. Stein. 2003. Evaluation of transgenic event Bt11 hybrid corn in broiler chickens. J. Poult. Sci., 82: 551-559.

Brophy, B., G. Smolenski, T. Wheeler, D. Wells, P. L'Huillier and G. Laible. 2003. Cloned transgenic cattle produce milk with higher levels of betacasein and kappa- casein. Nat. Biotech., 21: 157- 162.

Brundige, D.R., E.A. Maga, K.C. Klasing and J.D. Murray. 2008. Lysozyme transgenic goats' milk influences gastrointestinal morphology in young pigs. J. Nutrit., 138: 921-926.

Castro, M.C.R. e D. Glotz. 2002. Atualização em xenotransplantes. J. Bras. Nefrol., 24: 157160.

Chaves, A.L.S. 2006. Biologia molecular para iniciantes. $2^{\circ} e d$. Ed. Universitária-UFPel. Pelotas. $160 \mathrm{p}$.

Chaves, A.L.S., L. Augustin, M.F. Grando, M.I. Baggio-Fernandes e N. Langaro. 2003. Biossegurança de cultivos transgênicos. In: Plantas transgênicas na agricultura: do DNA ao agronegócio. Editora Umiversidade de Passo. Passo Fundo, RS. Brasil. 255 p.

Clark, J.H. and I.R. Ipharraguerre. 2001. Livestock performance: Feeding biotech crops. J. Dairy. Sci., 84 (E. Suppl.): 9-18.

Cromwell, G.L., R.D. Coffey and H.J. Monegue. 1993. Phytase (NatuphosTM) improves phytate phosphorus utilization in corn-soybean meal for pigs. J. Anim. Sci., 71 (Suppl. 1): 69 (Abstr. 158).

Cromwell, G.L., J.L. Pierce, T.E. Sauber, D.W. Rice, D.S. Ertl and V. Raboy. 1998a. Bioavailability of phosphorus in low-phytic acid corn for growing pigs. J. Anim. Sci., 76 (Suppl. 2): 58 (Abstr. 115).

Cromwell, G.L., J.L. Pierce, H.L. Stilborn, D.W. Rice, D.S. Ertl and V. Raboy. 1998b. Bioavailability of phosphorus in low-phytic acid corn for growing chicks. J. Poult. Sci., 77 (Suppl. 1): 117 (Abstr. S32).
Cromwell, G.L., S.L. Traylor, L.A. White, E.G. Xavier, M.D. Lindemann, T.E. Sauber and D.W. Rice. 2000. Effects of low-phytate corn and a low-oligosaccharide, low-phytate soybean meal in diets on performance, bone traits and phosphorus excretion by growing pigs. J. Anim. Sci., 78 (Suppl. 2): 72.

Cromwell, G.L., M.D. Lindemann, J.H. Randolph, G.R. Parker, R.D. Coffey, K.M. Laurent, C.L. Armstrong, W.B. Mikel, E.P. Stanisiewski and G.F. Hartnell. 2002. Soybean meal from Roundup Ready or convencional soybeans in diets for growing-finishing swine. J. Anim. Sci., 80: 708-715.

D'apice, A.J.F. and P.J. Cowan. 2008. Genemodified pigs. Xenotransplantation, 15: 87-90.

Flachowsky, G., I. Halle and K. Aulrich. 2005. Long term feeding of Bt corn - a 10 generation study with quails, Arch. Anim. Nutr., 59: 449-451.

Flachowsky, G., K. Aulrich, H. Bohme and I. Halle. 2007. Studies on feeds from genetically modified plant (GMP) - Contributions to nutritional and safety assessment. Anim. Feed Sci. Technol., 133: 2-30.

Folmer, J. D., R.J. Grant, C.T. Milton and J.F. Beck. 2000. Effect of Bt corn silage on short-term lactational performance and ruminal fermentation and dairy cows. J. Dairy. Sci., 83(5): 1182 (Abstr. 272).

Golovan, S.G., R.G. Meidinger, A. Ajakaiye, M. Cottrill, M.Z. Wiederkehr, D.J. Barney, C. Plante, J.W. Pollard, M.Z. Fan, M.A. Hayes, J. Laursen, J.P. Hjorth, R.R. Hacker, J.P. Phillips and C.W. Forsberg. 2001. Pigs expressing salivary phytase produce low-phosphorus manure. Nature, 19: 741-745.

Halle, I., K. Aulrich and G. Flachowsky. 2006. Four generations feeding of GMO-corn to laying hens. Proceeding of Society of Nutrition and Fisiology, 15: 114 (Abstract).

Hammond, B.G., J.L. Vicini, G.F. Hartnell, M.W. Naylor, C.D. Knight, E.H. Robinson, R.L. Fuchs and S.R. Padgette. 1996. The feeding value of soybeans fed to rats, chickens, catfish and dairy cattle is not altered by genetic incorporation of glyphosate tolerance. J. Nutr., 126: 717-727. Huang Y.J., Y. Huang, H. Baldassarre, B.Wang, A.Lazaris, M. Leduc, A.S. Bilodeau, A. Bellemare, M. Cote, P. Herskovits, M. Touati, C. Turcotte, L. Valeanu, N. Lemee, H. Wilgus, I. Begin, B. Bhatia, 


\section{XAVIER, LOPES E PETERS}

K. Rao, N. Neveu, E. Brochu, J. Pierson, D.K. Hockley, D.M. Ceras2oli, D.E. Lenz, C.N. Karatzas and S. Langermann. 2007. Recombinant human butyrylcho- linesterase from milk of transgenic animals to protect against organophosphate poisoning. In: Proc. Natl. Acad. Sci. U.S.A., 104: 13603-13608.

Hitz, W.D., T.J. Carlson, P.S. Kerr and S.A. Sebastian. 2002. Biochemical and molecular characterization of a mutation that confers a decreased raffinosaccharide and phytic acid phenotype on soybean seeds. Plant. Physiol., 128: 650-660.

Hyun, Y., G.E. Bressner, M. Ellis, A.J. Lewis, R. Fischer, E.P. Stanisiewski and G.F. Hartnell. 2004. Performance of growing-finishing pigs fed diets containing Roundup Ready corn (event nk603), a nontransgenic genetically similar corn, or convencional corn lines. J. Anim. Sci., 82: 571-580.

Hyvonen P, L. Suojala, J. Haaranen, W.A.Von and S. Pyorala. 2006. Human and bovine lactoferrins in the milk of recombinant human lactoferrintransgenic dairy cows during lactation. J. Biotechnol., 1: 410-412

James, C. 2007. Situação global das lavouras GM comercializadas: 2007. Disponível em: <http:// www.isaaa.org/resources/publications/briefs/ 37/executivesummary/pdf/Brief\%2037\%20\% 20Executive\%20Summary\%20\%20 Portuguese. pdf>. Acesso em: 10 de agosto de 2008.

Jacobs, C.M., P.L. Utterback, C.M. Parsons, D. Rice, B. Smith, M. Hinds, M. Liebergesell and T. Sauber. 2008. Performance of laying hens fed diets containing DAS-59122-7 maize grain compared with diets containing nontransgenic maize grain. Poult. Sci., 87: 475-479.

Kan, C.A. and G.F. Hartnell. 2004. Evaluation of broiler performance when fed Roundup-Ready wheat (Event MON 71800), control, and commercial wheat varieties. J. Poult. Sci., 83: 1325-1334.

Kies, K. 1999. Phytase- mode of action. In: Phytase in animal nutrition and waste management. $2^{\mathrm{B}} \mathrm{ed}$. BASF Corporation. New Jersey. p. 205-212.

Lai, L., J.X. Kang, R. Li, J. Wang, W.T. Witt, H.Y. Young, Y. Hao, D.M. Wax, C.N. Murphy, A. Rieke, M. Samuel, M.L. Linville, S.W. Korte, R.W. Evans, T.E. Starzl, R.S. Prather and Y. Dai. 2006. Generation of cloned transgenic pigs rich in omega-3 fatty acids. Nat. Biotech., 24: 435436.

Laible, G., B. Brophy, D. Knighton and D.N. Wells. 2007. Composition analysis of dairy products derived from clones and cloned transgenic cattle. Theriogenol., 67: 166-177.

Larson, S.R., K.A. Young, A. Cook, T.K. Blake and V. Raboy. 1998. Linkage mapping of two mutations that reduce phytic acid content of barley grain. Theor. Appl. Genet., 97: 141-146.

Li, Y.C., D.R. Ledoux, T.L. Veum, V. Raboy and D.S. Ertl. 2000. Effects of low phytic corn on phosphorus utilization, performance, and bone mineralization in broiler chicks. J. Poult. Sci., 79: 1444-1450.

Li, Y.C., D.R. Ledoux, T.L. Veum, V. Raboy and K. Zyla. 2001a. Low-Phytic acid barley improves performance, bone mineralization, and phosphorus retention in turkeys poults. J. Appl. Poult. Res., 10: 178-185.

Li, Y.C., D.R. Ledoux, T.L. Veum, V. Raboy, K. Zyla and A. Wikiera. 2001b. Bioavailability of phosphorus in low-phytic barley. J. Appl. Poult. Res., 10: 86-91.

Maga E.A., C.F. Shoemaker, J.D. Rowe, R.H. BonDurant, G.B. Anderson and J.D. Murray. 2006a. Production and processing of milk from transgenic goats expressing human lysozyme in the mammary gland. J. Dairy. Sci., 89:518-24.

Maga E.A., R.L. Walker, G.B. Anderson and J.D. Murray. 2006b. Consumption of milk from transgenic goats expressing human lysozyme in the mammary gland results in the modulation of intestinal micro-flora. Transgen. Res., 15: 515-519.

McCartney, E. 2004. Rastreabilidade na cadeia alimentar: Expectativas da União Européia. Biotecnologia nutricional na indústria de alimentação animal: Re-imaginando a indústria de alimentação animal. In: Anais do Simpósio Brasileiro da Alltech. Curitiba-PR. p. 34-42.

Mireles Jr, A., S. Kim, R. Thompson and B. Amundsen. 2000. GMO (Bt) corn is similar in composition and nutrient availability to broilers as non-GMO corn. J. Poult. Sci., 7 (Suppl. 1): 65-66 (Abstr. 285).

Moreira, M. A. 1998. Grãos transgênicos na alimentação animal. In: Anais do Simpósio Internacional sobre Nutrição de Aves. CampinasSP. p. 87-99. 


\section{ORGANISMOS GENETICAMENTE MODIFICADOS}

Nys, Y., D. Frapin and A. Pointillart.1999. Occurrence of phytase in plants, animals and microorganisms. In: Phytase in Animal Nutrition and Waste Management. $2^{\mathrm{a}}$ ed. BASF Corporation. New Jersey. p. 197-203.

Padgette, S.R., N.B. Taylor, D.L. Nida, M.R. Bailey, J. MacDonald, L.R. Holden and R.L. Fuchs. 1996. The composition of glyphosate-tolerant soybeans is equivalent to that of conventional soybeans. J. Nutr., 126: 702-716.

Pereira, L.V. 2008. Experimentação animal/Artigos: Animais transgênicos -Nova fronteira do saber. Disponível em: <http: //www.dol.inf.br/Html/ Edicao/Pdf/CartaLeitores6.pdf>. Acesso em: 10 de novembro de 2008.

Pierce, J.L.,G.L. Cromwell, T.E. Sauber, D.W, Rice, D.S. Ertl and V. Raboy. 1998a. Phosphorus digestibility and nutritional value of low-phytic acid corn for growing pigs. J. Anim. Sci., 76 (Suppl. 2): 54 (Abstr. 117).

Pierce, J.L., G.L. Cromwell and V. Raboy. 1998b. Nutritional value of low-phytic acid corn for finishing pigs. J. Anim. Sci., 76 (Suppl. 2): 177 (Abstr. 685).

Pierce, J.L. and G.L. Cromwell.1999. Effects of phytase on bioavailability of phosphorus normal and low-phytic acid corn. J. Anim. Sci., 77 (Suppl. 1): 60 (Abstr. 146).

Prather, R.S. 2006. Cloned transgenic heart-healthy pork? Transgen. Res., 5: 405.

Raboy, V. 2001. Seeds for a better future: "Low phytate" grains help to overcome malnutrition and reduce pollution. Trends Plant Sci., 6: 458462.

Raboy, V. 2002. Progress in breeding low phytate crops. Presented at the Symposium: Plant breeding: A new tool for fighting micronutrient malnutrition. Experimental Biology $2001 \mathrm{Mee}-$ ting. Orlando, FL. J. Nutr., 132: 503S-505S.

Raboy, V., P.F. Gerbasi, K.A. Young, S.D. Stoneberg, S.G. Pickett, A.T. Bauman, P.N. Murthy, W.F. Sheridan, and D.S. Ertl. 2000. Origin and seed phenotype of maize low phytic acid 1-1 and low phytic acid 2-1. Plant Physiol., 124: 355-368.

Russel, I. 2004. A "nova" biotecnologia: Usando tecnologias inovadoras para manter um planeta seguro. Biotecnologia Nutricional na Indústria de Alimentação Animal: Re-imaginando a indústria de alimentação animal. Anais do
Simpósio Brasileiro da Alltech. Curitiba-PR. p. 19-27.

Salamone, D., L. Baranao, C. Santos, L. Bussmann, J. Artuso, C. Werning, A. Prync, C. Carbonetto, C. Dabsys, C. Munar, R. Salaberry, G. Berra, I. Berra, N. Fernandez, M. Papouchado, M. Foti, N. Judewicz, I. Mujica, L. Munoz, S.F. Alvarez, E. Gonzalez, R. Zimmermann, M. Criscuolo and C. Melo. 2006. High level expression of bioactive recombinant human growth hormone in the milk of a cloned transgenic cow. J. Biotechnol., 124: 469-472.

Sebastian, S.A., P.S. Kerr, W. Pearlstein and W.D. Hitz. 2000. Soybean germplasms with novel genes for improved digestibility. In: Soy in Animal Nutrition. Ed. Federation of Animal Science Societies. Savoy, IL. p. 56-74.

Sidhu, R.S., B.G. Hammond, R.L. Fuchs, J. Mutz, L.R. Holden, B. George and T. Olson. 2000. Glyphosate-tolerant corn: The composition and feeding value of grain from glyphosate-tolerant corn is equivalent to that of conventional corn (Zea mays L.). J. Agric. Food Chem., 48: 23052312.

Spencer, J., G.L. Alee and T.E. Sauber. 2000a. Growing-finishing performance and carcass characteristics of pigs fed normal and genetically modified low-phytate corn. J. Anim. Sci., 78: 1529-1536.

Spencer, J.D., G.L. Alee, J.W. Frank and T.E. Sauber. 2000b. Nutrient retention and growth performance of pigs fed diets formulated with low-phytate corn and/or low-phytate/lowoligosaccharide soybean meal. J. Anim. Sci., 78 (Suppl. 2): 73 (Abstr. 211).

Spencer, J.D., G.L. Alee, T.E. Sauder, D.S. Ertl and V.Raboy. 1998. Digestibility and relative bioavailability of normal and genetically modified low-phytate corn (LP) for pigs. J. Anim. Sci., 76 (Suppl. 2): 54 (Abstr. 116).

Sugiura, S.H., V. Raboy, K.A. Young, F.M. Dong and R.W.Hardy. 1999. Availability of phosphorus and trace minerals in low-phytate varieties of barley and corn rainbow trout (Oncorhynchus mykiss). Aquacult., 170: 285-296.

Taylor, M.L., G.F. Hartnell, S.G. Riordan, M.A. Nemeth, K. Karunanandaa, B. George and J.D. Astwood. 2003a. Comparison of broiler performance when fed diets containing grain from YieldGard (MON810), YieldGard x Roundup 


\section{XAVIER, LOPES E PETERS}

Ready (GA21), nontransgenics control, or commercial corn. J. Poult. Sci., 82: 823-830.

Taylor, M.L., Y. Hyun, G.F. Hartnell, S.G. Riordan, M.A. Nemeth, K. Karunanandaa, B. George and J.D. Astwood. 2003b. Comparision of broiler performance when fed diets containing grain from YieldGard rootworm (MON863), YieldGard plus (MON810 x MON863), nontransgenics control, or commercial reference corn hybrids. J. Poult. Sci., 82: 823-830.

Vantreese, V. 2001. Biotechnology in our food system: Frequently asked questions and answers. Biotechnology Research and Education Initiative (BREI). Cooperative Extension Service. University of Kentucky. p.1-5.

Veum, T.L., D.R. Ledoux, D.W. Bollinger, V. Raboy and A. Cook. 2002. Low-phytic acid barley improves calcium and phosphorus utilization and growth performance in growing pigs. J. Anim. Sci., 80: 2663-2670.

Waldroup, P.W., J.H. Kersey, E.A. Saleh, C.A. Fritts, F. Yan, H.L. Stillborn, R.C. Crum Jr. and V. Raboy. 2000. Nonphytate phosphorus requirement and phosphorus excretion of broiler chicks fed diets composed of normal or high available phosphate corn with and without microbial phytase. J. Poult. Sci., 79: 1451-1459.

Wall, R.J., A.M. Powell, M.J. Paape, D.E. Kerr, D.D. Bannerman, V.G. Pursel, K.D. Wells, N. Talbot and H.W. Hawk. 2005. Genetically enhanced cows resist intramammary Staphylococcus aureus infection. Nat. Biotech., 23: 445-451.

Weber, T.E., B.T. Richert, D.C. Kendall, K.A. Bowers and C.T. Kerr. 2000. Grower-finisher performance and carcass characteristics of pigs fed genetically modified "Bt" corn. Purdue University, Swine Day Report. Disponível em: <http: // www.ansc.purdue.edu/swine/swineday/ sday00/psd07-2000.html>. Acesso em: 6 Abril 2001.

Xavier, E.G. 2003. Effects of phytase in diets containing low-phytate corn and soybean meal on performance, bone traits and phosphorus excretion of pigs and chicks. Ph. D. Dissertation. University of Kentucky. Lexington, KY. 252 p. Xavier, E.G., F. Rutz e P. Rossi.2005. Biotecnologia na nutrição animal: Grãos geneticamente modificados. In: XII Congresso Brasileiro de Veterinários Especialistas e Suínos. FortalezaCE. p 56-71. 